\title{
Teatro sem Vergonha: Jovens, Oficinas Estéticas e Mudanças nas Imagens de Si Mesmo
}

Theatre Without Shame: Youth, Aesthetic Workshops and Changes in Self Images

Teatro Sin Vergüenza:

Jóvenes, Oficinas Estéticas $Y$ Mudanzas en Las Imágenes de Sí Mismo

Janaína Rocha Furtado, Déborah Levitan, Andréia Piana Titon, Percy Francisco Velarde Castillo \& Andréa Vieira Zanella

Universidade Federal de Santa Catarina

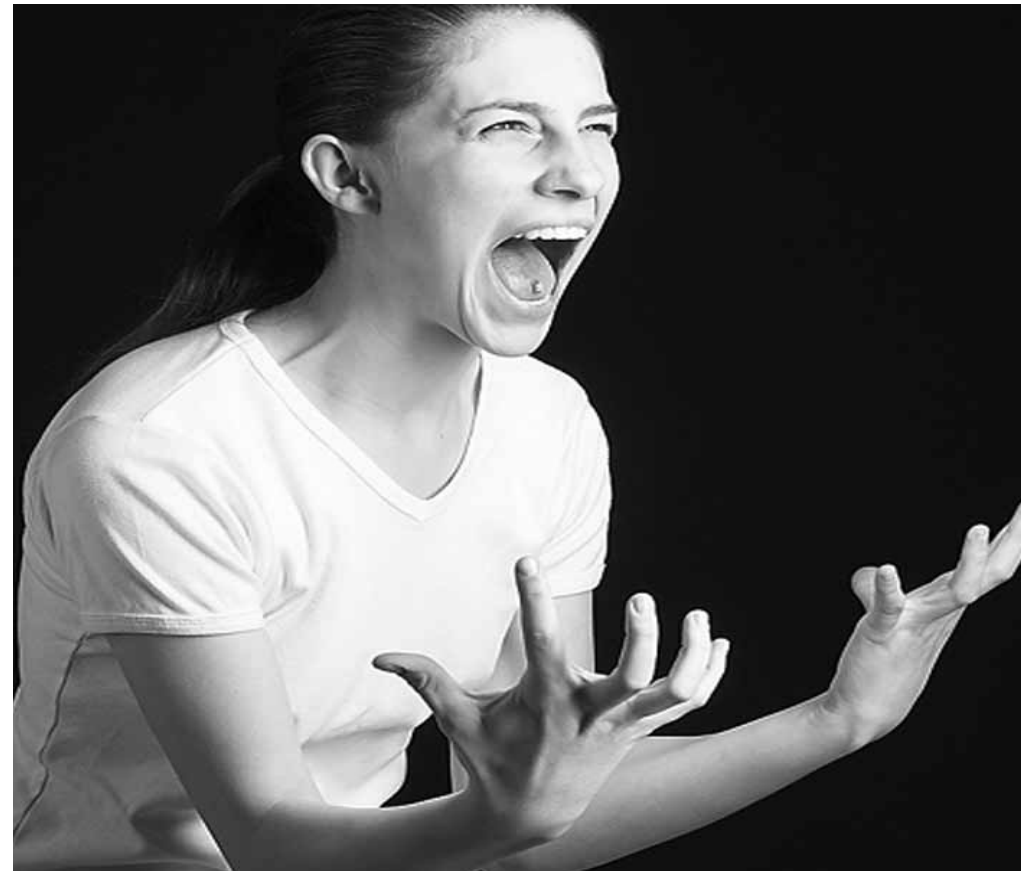


1. Cabe esclarecer que o termo sem vergonha do título não se refere ao sentimento de vergonha, mas sim, ao fato de a atividade teatral proposta aos alunos caracterizarse pela não pretensão de constituir arte. Optamos pela manutenção da expressão sem vergonha devido ao empobrecimento

linguístico que teria a expressão teatro sem pretensão, e a colocamos em itálico para chamar a atenção do leitor ao sentido que queremos dar a essa expressão.

2. Com a finalidade de resguardar as identidades dos sujeitos pesquisados, utilizaram-se nomes

fictícios, conforme consta no Termo de Consentimento Livre e Esclarecido.

Resumo: A importância da arte para o desenvolvimento humano e para a produção de mudanças nos modos de viver e de avaliar a realidade vem sendo cada vez mais reconhecida. Considerando a frequente utilização de atividades artísticas como meio e forma de intervenção no trabalho com jovens, objetivou-se, nesta pesquisa-intervenção, problematizar a potencialidade dessas atividades para a modificação da imagem de si mesmo que jovens apresentam. Uma oficina de improvisação teatral oferecida a jovens residentes em uma região periférica da cidade de Florianópolis, SC consistiu no lócus da pesquisa. Todas as oficinas foram filmadas, e foram coletadas informações com cinco jovens do sexo feminino por meio de entrevistas realizadas em dois momentos: no decorrer das primeiras semanas do curso e três meses após o seu término. Constatou-se que a oficina de improvisação teatral possibilitou, por um lado, expressar, apreciar e transformar os afetos e as vivências das jovens participantes; por outro lado, fez com que a arte de (re)criar estimulasse o diálogo entre as jovens participantes, pois promoveu caminhos e desafios diversos em relação ao (re)criar no exercício teatral e ao estar com um outro.

Palavras-chave: Teatro. Jovens. Imagem. Oficina criativa.

Abstract: The importance of art for human development and for the production of changes in the way of living and thinking about reality has been increasingly recognized. Considering the frequent use of artistic activities as a way and manner of intervention in the work with young people, this article aims to discuss the potentiality of those activities to change the images that young people present of themselves. A workshop of theatrical improvisation offered to young people that live in the periphery of Florianópolis was the locus of this research. All the workshops were filmed and it was collected information with five young girls in two different moments: in the beginning of the workshops and three months after it ended. We could verify that the theatrical improvisation workshops made possible, on one hand, to express, to appreciate and to transform the young participant's affects and experiences. On the other hand, the art of (re)creation stimulated the dialogue among the young participants, because it promoted ways and challenges related to the (re)creation in the theatrical exercises and in the contact with others.

Keywords: Theatre. Youth. Image. Creative workshop.

Resumen: La importancia del arte para el desarrollo humano y para la producción de mudanzas en los modos de vivir y de evaluar la realidad viene siendo cada vez más reconocida. Considerando la frecuente utilización de actividades artísticas como medio y forma de intervención en el trabajo con jóvenes, se objetivó, en esta pesquisa-intervención, problematizar la potencialidad de esas actividades para la modificación de la imagen de sí mismo que jóvenes presentan. Una oficina de improvisación teatral ofrecida a jóvenes residentes en una región periférica de la ciudad de Florianópolis, SC consistió en la localización de la pesquisa. Todas las oficinas fueron filmadas, y fueron colectadas informaciones con cinco jóvenes del sexo femenino por medio de entrevistas realizadas en dos momentos: en el transcurso de las primeras semanas del curso y tres meses después de su término. Se constató que la oficina de improvisación teatral posibilitó, por un lado, expresar, apreciar y transformar los afectos y las vivencias de las jóvenes participantes; por otro lado, hizo con que el arte de (re)crear estimulase el diálogo entre las jóvenes participantes, pues promovió caminos y desafíos diversos en relación al (re)crear en el ejercicio teatral y al estar con otro.

Palabras clave: Teatro. Jóvenes. Imagen. Oficina creativa.

Os jovens que moram nas comunidades periféricas dos complexos urbanos são (re) conhecidos muitas vezes pela sociedade, pela mídia e, não raro, pela produção científica como sinônimo de problema ou de risco, posto que geralmente são vinculados ao tráfico de drogas, ao roubo, à exploração sexual e ao crime. Considerando esses jovens em situação de risco, a partir da década de 80, a cooperação entre o CEPAL (Comissão Econômica para a América Latina e o Caribe), a ONU (Organização das Nações Unidas), os governos da Espanha e do Brasil vêm possibilitando o intercâmbio de experiências voltadas para a formação, a capacitação e o desenvolvimento de técnicas que possibilitem a realização de diagnósticos e discussões de políticas públicas para a juventude (Abramo, 1997).

A partir desses encontros, o governo do Brasil, com suas prefeituras e governos estaduais, vem incentivando e desenvolvendo projetos sociais voltados para os jovens. É frequente a presença de atividades artístico-criadoras nesses programas, como constatado por 
Castro, Abramovay, Rua e Andrade (2001). Segundo Azeredo (2003), os projetos que utilizam as linguagens artísticas como eixo central "são instrumentos poderosos de construção de valores, de identidades e de perspectivas de futuro" (p. 14), e, portanto, têm tido êxito nas suas ações. No entanto, pesquisa realizada por Urnau (2008) constata que as oficinas de arte são, muitas vezes, "desprovidas de conhecimentos de história, conceitos e técnicas de arte em suas diferentes linguagens, e a maioria das produções de arte feitas nas oficinas tem finalidades utilitárias" (p.124). Em consequência, geralmente a apropriação feita da arte pelas políticas públicas desconsidera a sua importância para o desenvolvimento psicossocial, aspecto esse destacado por Lev S. Vygotski (2001): "a vivência estética cria uma atitude muito sensível para os atos posteriores e, evidentemente, nunca passa sem deixar vestígios para o nosso comportamento" (p. 341).

Partindo do reconhecimento da importância da arte e dos processos de criação para o desenvolvimento humano, e, ao mesmo tempo, de seus limites quando transformada em objeto prático-utilitário, buscou-se, com esta pesquisa-intervenção fundamentada em pressupostos apontados por Rocha e Aguiar (2003), Maraschin (2004), Zanella e Sais (2008), compreender como esses jovens se percebem a partir das condições de vida em que estão inseridos e de que maneira os processos estético-criadores são mediadores na re-significação dessa percepção. Em artigo anterior, analisamos parte dos resultados da pesquisa, mais especificamente, os que permitiram evidenciar como essas jovens compreendem a juventude, as relações com a cidade em que vivem e as razões pelas quais optaram pela oficina de improvisação teatral (Levitan, Furtado, \& Zanella, 2009). Neste momento, objetivamos discutir a potencialidade de atividades de improvisação teatral para a modificação das imagens de si mesmo, a partir da análise dos resultados de uma intervenção com jovens que residem em uma região periférica da cidade de Florianópolis, SC.

\section{Imagens-de-si mesmo e atividades estético-criadoras: breves considerações}

As relações estéticas (ou sensíveis) e criativas - que congregam razão, afetividade, corpo e desejo - possibilitam ao sujeito estranhar a realidade vivida e, a partir desse distanciamento, produzir outra, mediada por novas significações que, uma vez apropriadas, podem contribuir para o redimensionamento e a re-significação do próprio viver/existir bem como para a transformação das imagens de si mesmo.

A atividade criadora se estabelece como um modo de ação humana no qual se objetivam as relações e os processos de singularização dos sujeitos. Como atividade contextualizada - marcada pelas idiossincrasias de sujeitos que, no processo, se interpelam, e pelas demais vozes sociais envolvidas, sejam silenciosas ou não, amalgamadas ou claramente distinguíveis - a atividade estético-criadora é sempre uma ação social, fruto de sujeitos inexoravelmente sociais que, inseridos historicamente em uma cultura, singularizam-se continuamente no movimento de apropriação dos modos coletivos nela existentes. Essa apropriação se dá mediada pela linguagem, ou seja, por processos de significação plurais, contraditórios e polissêmicos que possibilitam sua constituição.

Atividade criadora é, portanto, atividade em que se recria a própria realidade e o sujeito criador, ambos social e históricamente produzidos. Nessa perspectiva, considerase que a relação com um outro é fundante do próprio sujeito, a existência de um eu 
Segundo Vygotski (1992), "o pensamento e a palavra não estão relacionados entre si através de um vínculo primário. Essa relação surge, muda e cresce no transcurso do próprio desenvolvimento do pensamento e da palavra" (p.287). só é possível via relações sociais e, ainda que singular, é sempre e necessariamente marcada pelo encontro permanente com os muitos outros que caracterizam a cultura (Zanella, 2005).

Falar de imagem de si mesmo, portanto, requer a reflexão sobre a imagem que o outro faz do sujeito e que lhe apresenta, sendo esse outro considerado não necessariamente um outro identificável, reconhecível, mas o outro da cultura. Mídia, ciência, outros anônimos ou não, todos, de certa forma, participam da constituição das imagens sobre a realidade e sobre os próprios sujeitos. Essas imagens, por sua vez, são apropriadas em um movimento tal como o das palavras que, para Bakhtin (1990), são sempre palavras alheias tornadas próprias. Palavras, imagens, imagens/palavras que, como todo e qualquer signo, refletem a realidade e a refratam em um processo de criação no qual é incessantemente ressignificada.

Todo processo de criação se relaciona, por sua vez, com as experiências do sujeito que cria, com sua história e com a do contexto social do qual é parte/participa. Nesse sentido, Vygotski (1998) afirma que, quanto maior a experiência de vida, mais amplas serão as possibilidades de criação, pois essas experiências constituem subsídios com os quais se recria a própria realidade. As múltiplas combinações de fragmentos recortados de contextos e de condições várias, reconhecidos como significativos pelo sujeito que cria, possibilitam a emergência de algo novo que será, uma vez objetivado, base para novas e incessantes invenções.

$\mathrm{Na}$ improvisação teatral, por exemplo, é possível perceber nitidamente que a situação espontaneamente imaginada se fundamenta e é constituída por fragmentos da realidade que, por sua vez, atuam como dispositivos do processo de interpretação. Nesse processo, pensamento e memória se relacionam com os sentimentos e as emoções, e, destarte, são visibilizados na linguagem vocal e corporal da cena. Segundo Vygotski (1992), "o pensamento e a palavra não estão relacionados entre si através de um vínculo primário. Essa relação surge, muda e cresce no transcurso do próprio desenvolvimento do pensamento e da palavra" (p.287).

Assim, no exercício de criação teatral, o pensamento e a linguagem se concretizam no cenário, muitas vezes por meio da palavra, pois "o significado da palavra é a unidade de ambos os processos, que não admite mais decomposição e com relação à qual se pode dizer que representa: um fenômeno da linguagem ou do pensamento" (Vygotski, p. 289). O jogo de palavras na improvisação da cena evidencia, portanto, para além do conhecimento de técnicas teatrais, os pensamentos e as emoções dos sujeitos nela envolvidos.

O pensamento se (des)estrutura na relação com o outro na cena e converte-se em linguagem, sentimento e significado da palavra, desenvolvendo-se a cena teatral. Esse é o momento em que o pensamento e a palavra mudam no próprio processo da improvisação, uma vez que a composição mútua entre parceiros produz modificações relevantes nos sentidos das palavras provenientes das lembranças e histórias particulares bem como do intenso diálogo que toda e qualquer pessoa trava com os muitos outros com os quais se relaciona.

\section{Método}

Caracteriza-se esta pesquisa como intervenção, tanto pelo fato de o lócus da investigação ter sido constituído pelos pesquisadores (a oficina de teatro/improvisão) quanto pelas análises realizadas. A oficina de teatro/improvisação foi realizada através de encontros semanais, em uma associação de moradores de um bairro popular de Florianópolis, SC, com 
duração de aproximadamente três horas cada, por um período de três meses. Participaram da oficina entre cinco a dez jovens, todas do sexo feminino.

As jovens participantes costumavam frequentar a associação de moradores, local em que se realizavam diversas atividades. No semestre da referida pesquisa, ofereceu-se, nesse local, a oficina de teatro/improvisação, cuja divulgação foi feita através de cartazes colocados na própria associação de moradores e na escola da região.

Durante as tardes, as jovens que participaram da oficina frequentavam a associação de moradores e, no período da manhã, a escola do bairro em que residiam. Salienta-se que essas jovens moravam com as famílias, que, em sua maioria, são constituídas por um número significativo de irmãos e têm a mãe como centro do núcleo familiar. A associação de moradores constituía espaço fundamental na formação dessas jovens como sujeitos, sendo esse local comum e particular no que tange às relações interpessoais. Ali brincavam, jogavam, participavam de oficinas, encontravam as amigas e passavam parte do tempo juntas.

A oficina de teatro/improvisação tinha como objetivo investir nas relações entre as jovens participantes através do movimento de (re)criação de cenas em exercícios de improvisação teatral. Esses exercícios, por sua vez, visavam a possibilitar às jovens situações em que pudessem se reconhecer como capazes de criar e, ao mesmo tempo, reconhecer os outros com os quais criavam dialogicamente.

As atividades desenvolvidas em cada encontro compreendiam:

- Exercícios conduzidos ao trabalho grupal e também direcionados para a concentração do aluno-ator.
- Exercícios dirigidos ao desenvolvimento da rapidez física e mental: por exemplo, as participantes eram desafiadas a contar histórias com início, meio e fim em 2 minutos, depois em 1.

- Exercícios teatrais direcionados para as relações de confiança no outro.

- Jogos teatrais para que as alunas desenvolvessem a imaginação, partindo do pressuposto que as crianças e jovens brincam "ao sabor da fantasia" (Koudela, 1992, p. 45).

Para o desenvolvimento dos jogos teatrais, mencionavam-se inicialmente as regras do jogo para que as alunas pudessem trabalhar conjuntamente a construção do espaço e das personagens e estabelecessem relações de parceria. Isso implicava a observação do outro pelo aluno, desenvolvendo ele, nesse movimento, seus modos de ver/ouvir/sentir o outro e a si mesmo.

Após a explicitação das regras, apresentavamse temas a serem improvisados e ao mesmo tempo problemas na improvisação, posto que "a solução do problema implica o esforço dos jogadores para chegar até o desenlace e a improvisação espontânea de ações, para vencer o imprevisto" (Koudela, 1992, p. 48). Após as improvisações, era aberto espaço para que as alunas compartilhassem suas dificuldades, as quais consistiam fonte para o desenvolvimento de exercícios destinados a suprir essas lacunas e assim a continuar o processo de improvisação/criação teatral.

Cada encontro seguia uma organização prévia, que compreendia: exercícios de aquecimento, de reconhecimento de si mesmo e do outro, atividades de improvisação teatral, com temáticas que emergiam das próprias participantes ou que eram propostas pelo mediador da oficina, e avaliação do encontro, geralmente 
Para Bakhtin (1990) e Vigotsky (2000), a palavra resulta sempre da interação entre sujeitos e dos diversos sentidos nela envolvidos, e, por ser a palavra sempre polissêmica, os sentidos só podem ser compreendidos, portanto, dialogicamente. feito de forma oral. Essa organização era geral, posto que a improvisação também caracterizava o próprio desenvolvimento da oficina: necessário se fazia ouvir/ver/sentir os acontecimentos para propor atividades que provocassem deslocamentos nos modos de estar com outros, condição fundamental para que a constituição de cenas teatrais por meio do improviso pudesse ocorrer.

Todos os encontros foram registrados em filmagens, e também foram coletadas informações com as jovens por meio de entrevistas individuais, realizadas na própria associação de moradores em horários variados, a depender da disponibilidade das jovens. As entrevistas constaram de dois momentos: no decorrer das primeiras semanas do curso e três meses após o seu término. Todas foram gravadas com o auxílio de um aparelho gravador digital e de uma filmadora e transcritas integralmente.

A escolha pela videografia como recurso para o registro de informações sustenta-se em sua capacidade de captar grande quantidade de ações e falas dos sujeitos, permitindo o acompanhamento detalhado das relações interpessoais e dos processos psicológicos presentes (Meira, 1994).

Após a realização das oficinas, foi gravado um DVD para cada participante, com duração de aproximadamente 10 minutos, que continha imagens dos momentos vividos pelas jovens nas oficinas. Esse DVD caracterizava-se por uma compilação de imagens de cada jovem em diversos momentos das oficinas, embalados ao ritmo de músicas que davam o tom à sua participação.

A cópia do DVD foi entregue a cada participante no início da entrevista final e, após ser assistido em conjunto - entrevistador e jovem - consistiu material para o próprio desenvolvimento da entrevista. De modo geral, esse material possibilitava que as jovens, ao se verem no DVD, revisitassem as atividades realizadas nas oficinas e sua participação, e constituiu, assim, dispositivo para as falas dos sujeitos relacionadas aos objetivos da pesquisa.

Após a transcrição de todas as entrevistas, iniciou-se a análise dos dados com o mapeamento dos discursos das jovens a partir dos temas e das questões emergentes, o que possibilitou o delineamento de unidades temáticas de análise. A análise dessas unidades, tendo as teorias de Bakhtin (1990) e Vygotski (2000) como referência analítica, possibilitou compreender as tensões entre as várias vozes sociais que se fizeram ouvir nos discursos das jovens.

Para Bakhtin (1990) e Vigotsky (2000), a palavra resulta sempre da interação entre sujeitos e dos diversos sentidos nela envolvidos, e, por ser a palavra sempre polissêmica, os sentidos só podem ser compreendidos, portanto, dialogicamente. O que define a especificidade dialógica do discurso é que ele sempre se dá na relação de alteridade, onde eu/outro se interpenetram, se definem, sem, no entanto, se fundirem, refratando e refletindo uma dada realidade. $\mathrm{O}$ discurso produz-se, então, como ato em um contexto singular e irrepetível que possibilita e impossibilita a emergência de certos enunciados, entendidos como unidades reais da comunicação discursiva (Bakhtin, 1990) ou unidades temáticas. No discurso, apresentase, por sua vez, não somente a voz do sujeito que fala, mas, intrinsecamente, a voz do outro a quem responde e muitas outras vozes sociais que participam do diálogo e com as quais, consciente ou inconscientemente, se estabelece interlocução. 


\section{Resultados}

"A vida só

é possível reinventada"

(Cecília Meirelles)
Tendo em vista que "sentimento e pensamento movem a criação humana" (Vygotski, 1998, p. 25), a relação sensível entre pessoas no processo de dramatizar, integrando as dimensões afetivas, cognitivas e motoras, é aspecto fundamental do processo de criação e re-criação. Ao atuarem coletivamente como cocriadores de novos sentimentos, pensamentos e palavras, objetivados em cena por meio de várias linguagens, verbais e corporais, as jovens atuaram também sobre si mesmas, revisitando-se e reinventando-se ao mesmo tempo.

É interessante perceber que, nesse movimento, em se tratando dos aspectos da realidade que atuam como material de base para a (re) criação das jovens, a televisão, especialmente as novelas, se destacou. De fato, as novelas representam, no contexto brasileiro, potentes articuladoras de vozes que organizam e constroem os processos simbólicos, políticos, morais e estéticos da sociedade ocidental conduzindo sentidos por meio de um formato universalizante de produção de narrativa (Borelli, 2001). Ao instituírem territórios entre ficcionalidade e realidade, produzem e fazem veicular discursos diversos, direcionando os sentidos do espectador em relação ao conteúdo áudio-visual tratado. Por sua vez, fabricam desejos, anseios, constroem e partilham perspectivas de futuro e criam um imaginário acerca de vários aspectos da vida: relações amorosas, profissionais e familiares, entre outras (Fischer, 2005).

Por meio da observação das oficinas e das análises das entrevistas, foi possível perceber que as jovens traziam, em diversos momentos das cenas protagonizadas, temas cotidianos e problemas reais que vivenciavam no bairro no qual residem, mas, especialmente, temas e questões que advinham das imagens da televisão. Elas imitavam as suas personagens preferidas ou os dilemas abarcados nas novelas, porém essa imitação era acrescida das pautas das suas experiências cotidianas.

Na cena dramatizada na oficina, que revivia o drama encenado na $\mathrm{TV}$, as jovens repetiam os discursos, os conflitos, as contradições e viviam por elas, nelas mesmas, as várias situações que, de uma ou outra forma, as haviam afetado anteriormente. Como bens culturais ativamente consumidos pelas jovens, as novelas se apresentaram, então, como elementos significativos, no espaçotempo das oficinas, para a (re)invenção de si mesmas. Destaca-se, no entanto, que, além de imitar e (re)viver as personagens, as jovens as recriavam, pois faziam as personagens protagonizarem suas histórias particulares, de modo que as personagens se mesclavam, as histórias se amalgamavam e os afetos se perdiam e se achavam em uma criação outra, que favorecia, por sua vez, uma re-criação ativa de seus próprios afetos e pensamentos.

Esse movimento pode ser visualizado com a ajuda de Fabiana ${ }^{2}$, que, ao responder à pergunta sobre qual momento da oficina mais gostou, respondeu: "quando a gente fez a novela X". Posteriormente, após ser questionada sobre o que sua mãe dizia sobre o fato de ela fazer teatro, Fabiana relata:

Fabiana: - Eu sempre falava pra ela que tava fazendo teatro, aí ela bem assim 'ah, tu pode ser atriz, quando tu crescer!'

Entrevistadora: - E tu gostarias de ser atriz? Fabiana: - Sim.

Entrevistadora: - Atriz de televisão?

Fabiana: - Aham.

Entrevistadora: - Tu gostarias de ser como alguma atriz que você conhece? Tem alguém que você olha e diz que quer ser que nem ela?

Fabiana: - A Maria, do Rebeldes.

Fazer teatro apresentava-se, também, como uma possibilidade de adquirir conhecimento para uma profissão futura estreitamente 
vinculada à televisão e ao imaginário constituído acerca do tripé fama, trabalho, atriz. Atuar promovia, assim, forjado nesse imaginário ir-real, o projetar-se no futuro, um vir-a-ser. Nos caminhos desse deviratriz, algumas dessas jovens re-inventavam o seu cotidiano, de juventude de periferia, transformando os espaços-tempos já conhecidos, revisitando espaços-tempos outros, nos quais outras se faziam.

Assim sendo, no decorrer das oficinas, pudemos perceber que as alunas transformaram a improvisação em uma história que refletia a sua própria vida e os seus conflitos. Se, por um lado, era interessante conhecer as histórias ali vivenciadas, por outro lado, perdia-se o foco do processo da criação coletiva, pois cada jovem permanecia centrada em si, em seus dilemas cotidianos. Ao se preocuparem demais com seus pensamentos, com sua própria linguagem, enredadas em passados e hábitos, elas deixavam de perceber o outro com o qual contracenavam.

Foi necessário, portanto, sensibilizar as participantes para olhar o outro utilizando exercícios teatrais dirigidos ao trabalho em conjunto, uma vez que, “(...) ao nos colocarmos no papel do outro, o teatro nos dá possibilidade de conhecer melhor o outro e si mesmo e os 'outros' que nos rodeiam, e de aprender a abarcar as diferenças em vez de tentar eliminá-las" (Strazzcappa \& Vianna, 2001, p.121).

A partir de então, as jovens começaram a prestar mais atenção nas colegas, a trocar e a completar a cena protagonizada pelo outro, o que foi possível com a escuta do que dizia/fazia/sentia sua companheira de cena. Com essa escuta do outro, as jovens compreenderam a narrativa em curso para, a partir do que se apresentava em processo, dar continuidade à criação da história.
Além desse movimento em relação ao outro, foi possível, com as análises, observar o movimento das próprias jovens, como destaca Valéria: "a gente perdeu um pouco de vergonha também". Poliana reitera essa possibilidade de transformação do teatro: "agora, que eu fiz teatro, eu não tenho mais vergonha de ficar na frente dos outros. Antes eu tinha vergonha de ficar na frente de tudo mundo. Mas agora, não".

A fala de Poliana leva-nos a entender que há uma posição no seu discurso sobre o medo de estar frente ao outro, e essa mudança emerge no processo de querer arriscar-se no movimento da criação. Esse atrever-se a criar pode emergir provocado pelo gesto, pelo olhar, pela ideia e pela escuta das palavras e contra-palavras do outro. A jovem, também, conseguiu escutar, ver e assumir uma posição diante das ações, das sugestões e emoções do outro, e distanciar-se dela mesma.

Os discursos dessas jovens sinalizam a possibilidade de mudança propiciada pela atividade proposta, uma vez que, no processo das oficinas, ao se exporem aos outros, elas puderam aprender pouco a pouco a deixar de se sentir vulneráveis quanto aos êxitos e fracassos que caracterizam todo e qualquer processo de aprendizagem.

Aos poucos, as alunas-atrizes passaram a compreender que o processo de improvisação emerge e se desenvolve com a mediação do outro e que, por sua vez, se trabalha na cena para ver/ouvir/escutar o outro. O outro, cujo olhar podia ver o seu corpo inteiro, como um todo acabado, e para o qual se tornavam uma (Bakhtin, 1990), esse olhar do outro com seus valores e para o qual o corpo de cada uma delas - como vivência interna - pouco a pouco se transformava. Com essa aprendizagem, as jovens foram paulatinamente modificando o modo de agir. Isso ocorreu porque, quando o aluno-ator começa a entender a improvisação como processo de criação 
com o outro, seu pensamento e emoções se entrelaçam às emoções e pensamentos do companheiro, e é dessa maneira que pode ver/ouvir/sentir o que este quer dizer. Em outras palavras, conseguem criar com o outro sem restrições, porque, como bem destaca Poliana: "aprendemos a interpretar as pessoas, aprendemos a nos desenvolver melhor".

Ao mesmo tempo, é possível identificar igualmente o processo de re-criação de si mesmo, através da percepção de mudanças nas jovens cujos corpos, pelos jogos de improvisação, ganharam expressividade. Poliana reconhece a importância dos exercícios teatrais e da convivência criativa com os outros para a modificação de si mesma, e, assim como essa jovem, a análise das filmagens evidenciou mudanças nas participantes ao término das oficinas. Observou-se que estavam mais atentas ao que se dizia e fazia na improvisação. Os corpos, mais soltos, dialogavam, encarnavam e materializavam algumas das mudanças produzidas, o que foi percebido por outros significativos, como a mãe de Poliana:

Poliana: - Ela que falou. Ela falou que eu melhorei em tudo (...) Que eu não tenho mais preguiça de lavar a louça, limpar a casa.

Entrevistadora: - É por causa do teatro? Poliana: - Aham.

Entrevistadora: - E tu achas que a tua mãe está certa?

Poliana: - Acho que sim.

Esse corpo re-experimentado no teatrooficina em suas possibilidades transformouse em corpo potência em outras situações, inclusive as banais e triviais, corpo-sujeito, então, re-inventado. A oficina de teatro apresentou-se, por conseguinte, como viabilizadora de relações com a alteridade, isso porque a improvisação é uma situação dialógica por excelência, pois permite fazer réplicas ao dito, confrontar posições, dar acolhida fervorosa à palavra do outro, confirmá-la ou rejeitá-la, buscar-lhe um sentido profundo, ampliá-la, em suma, estabelecer com a palavra de outrem relações de sentido de determinada espécie, isto é, relações que geram significação responsivamente a partir do encontro de posições avaliativas (Faraco, 2006, p. 64)

\section{Oficinas estético-criadoras: a arte como mediadora dos processos de constituição do sujeito}

Como destacado anteriormente, é por meio das experiências vivenciadas pelo sujeito, ou seja, pela sua história, socialmente produzida, que ele se constitui. E são essas mesmas experiências que fornecem o material para o sujeito transgredir o criado e inventar novas possibilidades de ser, de estar no mundo, ou seja, de recriar sua história e de vivenciar novas experiências.

O potencial da arte, e poderíamos dizer, das experiências estético-criadoras, vem sendo explorado em diferentes projetos sociais, pois se reconhecem as potencialidades dessas atividades na transformação das relações entre os sujeitos assim como na a invenção de novas possibilidades de existência. Conforme Sposito, Carvalho e Souza (2006), nos programas desenvolvidos no Brasil, nas duas últimas décadas, voltados para jovens, em primeiro lugar, estão atividades direcionadas para o acompanhamento e a reinserção social, e, em segundo, propostas de cunho artístico como a dança, o teatro, a música e as artes plásticas.

No entanto, é fundamental discutir o caráter dessas atividades para além de suas finalidades imediatas, já que deve estar comprometido com o desenvolvimento de um ser humano integral. De acordo com 
Sposito et al. (2006), parte dessas ações voltadas para a cultura não apresenta objetivos nessa área, mas são usadas como estratégias para outros fins que não os artísticos, como para conter a violência, a agressividade, por exemplo. Em outra perspectiva, defende-se o direito a uma formação estética, que amplie o acesso a bens culturais produzidos pela humanidade (Zanella, 2007). Nessa perspectiva, também podemos enfatizar as necessidades humanas para além da própria sobrevivência.

Vygotski (2001) faz uma crítica ao ensino de artes com perspectiva moralizante, e propõe que este promova determinadas habilidades técnicas da arte e, ao mesmo tempo, possibilite o desenvolvimento de habilidades para a apreciação estética. Além disso, o autor sugere que a educação estética seja inserida na própria vida, no cotidiano: “(...) o que deve servir de regra não é o adornamento da vida, mas a elaboração criadora da realidade, dos objetos e seus próprios movimentos, que aclara e promove as vivências cotidianas ao nível de vivências criadoras" (p. 352).

A riqueza de atividades como o teatro/ improvisação, discutido neste trabalho, pode ser encontrada na perspectiva do desenvolvimento de um sujeito que vai além de sua racionalidade, tão valorizada na cultura ocidental, um sujeito constituído de racionalidade, afetividade, corporalidade. Observa-se, no relato das participantes, a ênfase dada a essa questão, ao dizerem que preferem participar de oficinas de teatro, dança, futebol, por exemplo - atividades que envolvem o corpo -, do que de outras atividades como uma aula de informática.

No caso das oficinas descritas neste trabalho, percebe-se que a metodologia do trabalho com improvisação envolve a integração entre aspectos de percepção, memória, cognição, imaginação e a ação dos participantes. Isso abre possibilidades para o sujeito transformar-se nessa ação e se diferencia de outras atividades descoladas do movimento, da ação que, muitas vezes, mantém a disciplina e a domesticação dos corpos.

Uma das participantes, ao ser questionada pelas pesquisadoras sobre como era frequentar a associação de moradores, destaca:

Vanessa: - Eu escolheria vir pra associação de moradores do que ir para a escola. (...) Porque ficar o dia todo, fica cinco períodos, sentado numa cadeira só copiando. Isso é um tédio. Daí eu não gosto de ficar só copiando.

Entrevistadora: - E o que tu faz aqui na associação de moradores que tu gosta, então? Pra tu preferir vir pra associação de moradores?

Vanessa: - Tem bijuteria e, não sei, é que a gente não fica só sentada, só copiando.

Observa-se no discurso dessa jovem a importância de atividades que vão além da disciplinarização e da reprodução: "só sentada, só copiando". Por outro lado, podemos resgatar a importância de práticas educativas que possibilitem aos sujeitos ir além da mera reprodução acrítica dos conhecimentos, que estejam voltadas para a re-criação dos conhecimentos produzidos historicamente pela humanidade.

Molon (2006), em um trabalho com formação de professoras, destaca a conclusão destas sobre “(...) o quanto a corporeidade é percebida como lugar de dominação e o quanto a aprendizagem está vinculada estritamente à permanência de corpos sem movimentos, com desejos e atitudes controlados" (p. 104). Destaca ainda a corporeidade como construção social e histórica, e não apenas como um aparato biológico. 
Outra questão relacionada à constituição dos sujeitos e às atividades criadoras é relativa à imaginação. Nos discursos das participantes, podemos observar isso quando se referem às brincadeiras, aos jogos de teatro que vivenciaram. Ao serem questionadas sobre como foi a participação nas oficinas de teatro/ improvisação, relatam:

Vanessa: - (...) Eu gosto das brincadeiras,... gosto daqueles teatrinhos que a gente faz.

Fabiana: - Lembro das brincadeiras, das fotos que a gente fazia e das brincadeiras lá fora que a gente fazia de esporte. (...) Das brincadeiras em sala, de fazer teatrinho. A gente fez a novela " $x$ ". E o professor gostou.

Poliana: - As brincadeiras. (...) Aquela que tinha que fingir que tava brigando.

Um aspecto fundamental a ser considerado nesses jogos e brincadeiras é a imaginação ali envolvida. Vygotski (1998) afirma que a imaginação ou fantasia tem lugar central nos processos de criação, pois tudo o que existe culturalmente, ou seja, toda produção/ criação humana nesta se baseia. A atividade criadora permite ao sujeito re-elaborar e (re)criar, com elementos de experiências passadas, novas formas no seu cotidiano, assim como se projetar no futuro através da imaginação.

O autor destaca que a possibilidade de criar é característica de todos os seres humanos, não é exclusiva dos grandes gênios e artistas, e está presente desde os primeiros anos da infância. A capacidade criativa das crianças, conforme Vygotski (1998), é uma das questões centrais da Psicologia infantil e da pedagogia, assim como a importância de estimular a imaginação e a criação para o desenvolvimento infantil. Nos jogos, a imitação, a imaginação e a criação permitem à criança não somente reproduzir o que vê, mas, a partir das lembranças do vivido, criar novas possibilidades para situações cotidianas, daí a necessidade de ampliar as experiências das crianças se queremos proporcionar-lhes diferenciadas bases para sua atividade criadora.

No caso do trabalho com jovens como as que participaram das oficinas de teatro/ improvisação, destaca-se a importância tanto de oficinas artísticas como do acesso a diferentes espaços, lugares e contextos que possibilitem a ampliação de suas experiências. Essa questão é fundamental, se considerarmos as restrições ao acesso que as cidades oferecem para pessoas de baixa renda.

Outra questão importante em propostas como das oficinas de teatro/improvisação está relacionada com a criação de espaços que potencializam a transformação de si mesmo através da relação com o outro, em um contexto de intersubjetividades que possibilite a ressignificação de uma determinada condição do sujeito. Nesse caso, a relação com um outro é fundamental, pois é através dessas relações que são criadas oportunidades de se mostrar ao outro e de transformar seu modo de se posicionar diante dele.

Uma das participantes destaca, ao ser questionada sobre o que diria para convencer outra pessoa a participar de uma oficina de teatro: "eu só falaria que era legal e que ela devia ir. (...) Porque é legal pra ela aprender a se soltar mais, a brincar." Nesse caso, podemos ver o reconhecimento desse tipo de atividade pela jovem como uma possibilidade de transformação de si mesma, o que provavelmente ocorreu devido à sua participação nas oficinas. Podemos pensar também na questão da timidez enfatizada pelas participantes:

Entrevistadora: - E para você, como é o teatro? 
Poliana: - Ah, pra mim, é legal. Porque eu não tenho vergonha. (...) Também porque só tem gente que eu conheço.

Fabiana: - Eu acho que tô mais solta.

(...) Menos tímida. Por causa que eu não gostava muito de câmera. (...) No começo, eu não ia por causa que tinha vergonha. Daí me convidaram pra ir e eu fui. (...)

Vanessa: - (...) Eu era bem tímida. Não fazia nada, queria só ficar sentada.

Foi através da participação frequente em atividades promovidas pela associação de moradores que elas entraram em contato com a oficina de teatro/improvisação que estava sendo oferecida. Portanto, o contexto em que se encontravam era familiar, uma vez que já haviam participado de diversas outras oficinas naquele local, como dança, maracatu e bijuteria, entre outras. A proposta da oficina de teatro se apresentou para alguns como um universo ainda não conhecido, e o objetivo desta última era justamente promover, de uma forma ou de outra, uma ruptura nos sentidos relacionados à juventude e às imagens de si mesmo.

O teatro seria a forma-expressão mediadora do movimento de desnaturalização das imagens cristalizadas, geralmente criadas a partir dos estigmas e preconceitos veiculados na mídia, recriando outras imagens e ampliando os sentidos acerca da juventude e seus processos. Objetivava que, por meio da expressão corporal e da possibilidade performática de adotar outros perfis, as jovens se abrissem para novas maneiras de dar significado à realidade e de projetar-se para o futuro e para o seu vir-a-ser.

Há, no entanto, ressalvas quanto a esse papel do teatro e do que foi possível produzir de mudanças nas imagens sobre si mesmo. Pôde-se perceber, na análise das entrevistas realizadas em dois momentos diferentes, que os discursos das jovens sobre a participação nas oficinas de teatro/ improvisação destacaram um caráter utilitário ("melhorou isso, porque posso agora ser atriz" ou "porque aprendi a mentir, e agora posso enganar minha mãe"), acompanhado de uma dificuldade da percepção da modificação de sua autoimagem.

As jovens não perceberam o desenvolvimento da capacidade de imaginar e criar que tal tipo de atividade propicia. Talvez esse discurso reflita a crença predominante em nossa cultura de que a criação é prerrogativa para certas pessoas de talento, em vez da compreensão de que criar consiste em fazer algo novo e é, dessa forma, possível a todos, em maior e menor grau.

\section{Considerações Finais}

É importante destacar, à guisa de conclusão, que, em qualquer idade, é fundamental participar de contextos caracterizados por atividades criadoras e relações dialógicas, porque se sabe que a arte contribui positivamente para o desenvolvimento psicossocial, possibilitando expressar, apreciar e transformar os afetos e vivências e sendo capaz de atuar para transformar os seres humanos e suas relações, enfim, seus modos de estar no mundo.

Essas transformações, de certa forma, aconteceram na oficina de teatro/improvisação teatral aqui analisada. Constatou-se que a arte de (re)criar estimulou o diálogo entre as jovens participantes, pois promoveu caminhos e desafios diversos em relação ao (re)criar no exercício teatral e ao estar com um outro. As diversas possibilidades de cenas que emergiram foram valorizadas, sendo que o processo de (re)criar a cena foi marcado pelo encontro com a diferença e resultou na construção das possibilidades de criação mediadas pelo outro. 
Em relação aos objetivos da pesquisa, no entanto, há que se considerar com cuidado o que o curso possibilitou no que se refere às modificações nas imagens de si mesmo. A esse respeito, constatou-se que os discursos das jovens entrevistadas demonstram subreptícias modificações nas imagens de si mesmas, porém é necessário que se problematize algumas questões.

Por um lado, considera-se fragilidade as poucas oficinas ministradas, o curto espaço decorrido entre as entrevistas iniciais e finais, que denotam limitações no desenho da pesquisa. Tem-se também a participação flutuante das jovens, as preocupações características de jovens nessa faixa etária e a (in)flexibilidade das relações características do contexto em que vivem, que foram significativas para a (in)viabilização das mudanças investigadas. Por outro lado, os dados colhidos das entrevistas iniciais e finais permeiam condições de possibilidade específicas, dispositivos forjados pela pesquisa, em relação ao falar sobre si mesmo e ao fato de não serem capazes, por si próprios, de representar todas as mudanças e nuances que se operam em um sujeito em transformação.

De qualquer maneira, os resultados dessas entrevistas permitem compreender a trama intrincada das relações e vozes sociais que participam do processo de constituição da imagem de si mesmo dos jovens investigados, bem como as mediações para sua transformação. Atividades estético-criadoras, por sua vez, podem vir a ser importantes ferramentas nesse movimento, porém necessário se faz considerar: as condições em que essas atividades ocorrem, as relações estabelecidas com outros participantes e com a pessoa que ocupa o lugar de professor nesse contexto e o modo como as jovens dão significado a essas atividades.

Janaína Rocha Furtado

Doutoranda do Programa de Pós-Graduação em Psicologia da USFC, Psicóloga, Santa Catarina - SC - Brasil. E-mail: janarf1@yahoo.com.br

\section{Déborah Levitan}

Bacharel em Psicologia pela Universidade Federal de Santa Catarina - UFSC, Psicóloga,

Santa Catarina - SC - Brasil.

E-mail: delevitan@gmail.com

\section{Andréia Piana Titon}

Mestre em Psicologia pela Universidade Federal de Santa Catarina (UFSC), Psicóloga, Santa Catarina - SC -

Brasil.

E-mail: andreiatiton@sst.sc.gov.br : andreiatiton@yahoo.com.br

\section{Percy Francisco Velarde Castillo}

Mestre em Psicologia pela Universidade Federal de Santa Catarina (UFSC), Educador, Santa Catarina, SC Brasil.

E-mail: percasve@yahoo.es

\section{Andréa Vieira Zanella}

Doutorado, Docente da graduação e do Programa de Pós-Graduação em Psicologia da UFSC, bolsista em produtividade do CNPq, Santa Catarina - SC - Brasil.

E-mail: azanella@cfh.ufsc.br

\section{Endereço para envio de correspondência:}

Rua das Palmeiras Nativas, no200- Lagoa da Conceição, Florianópolis, SC - Brasil CEP 88062-010 


\section{Referências}

Abramo, H. W. (1997). Considerações sobre a tematização da juventude no Brasil. Revista Brasileira de Educação, 5/6, 25-36.

Azeredo, B. (2003). Estratégia social em favelas e periferias urbanas. In Anais do XV Fórum Nacional - o novo Governo, novas prioridades e crescimento sustentado (pp.1-24). Rio de Janeiro.

Bakhtin, M. (1990). Marxismo e filosofia da linguagem. São Paulo: Hucitec.

Borelli, S. H. S. (2001). Telenovelas brasileiras: balanços e perspectivas. São Paulo em Perspectiva, 15(3).

Castro, M. G., Abramovay, M., Rua, M. G., \& Andrade, E. R. (2001). Cultivando vida, desarmando violências: experiências em educação, cultura, lazer, esporte e cidadania com jovens em situações de pobreza. Brasília, DF: UNESCO.

Faraco, C. A. (2006). Linguagem e diálogo: as idéias lingüísticas do círculo de Bakhtin (2a ed.). Curitiba: Criar.

Fischer, R. M. B. (2005). Mídia e juventude: experiências do público e do privado na cultura. Caderno CEDES, 25(65), 43-88.

Koudela, I. (1992). Jogos teatrais. São Paulo: Perspectiva.

Levitan, D., Furtado, J. R., \& Zanella, A.V. (2009). Jovens, imagens de si e a cidade: discursos em movimento. Revista Brasileira de Crescimento e Desenvolvimento Humano, 19(2), 283-296.

Maraschin, C. (2004). Pesquisar e intervir. Psicologia e Sociedade, 16(1), 98-107.

Meira, L. (1994). Análise microgenética e videografia: ferramentas de pesquisa em psicologia cognitiva. Revista Temas em Psicologia: questões teórico-metodológicas, 3, 59-71.

Molon, S. I. (2006). Subjetividade, sujeito e atividade criadora: questões para a formação continuada de educadores(as) na abordagem sócio-histórica. In S. Da Ros, K. Maheirie \& A. V. Zanella (Orgs.), Relações estéticas, atividade criadora e imaginação: sujeitos e (em) experiência. (pp. 95-116). Florianópolis: NUP/CED/UFSC.

Rocha, M. L., Aguiar, K. F. (2003). Pesquisa-intervenção e a produção de novas análises. Psicologia Ciência e Profissão, 23(4), 64-73.

Sposito, M. P., Carvalho, H. H. de, \& Souza, N. A. (2006). Juventude e poder local: um balanço de iniciativas públicas voltadas para jovens em municípios de regiões metropolitanas. Revista Brasileira de Educação, 11(32), 238-257.
Strazzcappa, M., \& Vianna, T. (2001). Teatro na educação: reinventando mundos. In S. Ferreira (Org.), O ensino das artes: construindo caminhos. Campinas, SP: Papirus.

Urnau, L. C. (2008). Juventude e arte: os sentidos da mediação artística para jovens participantes de projetos sociais. Tese de mestrado, Curso de Pós-Graduação em Psicologia, Universidade Federal de Santa Catarina, Florianópolis.

Vygotski, L. S. (2000). Obras escogidas. Problemas del desarrollo de la psique. (Vol. 3). Madrid: Visor Distribuciones.

Vygotski, L. S. (1992). Pensamiento y palabra. In L. S. Vygostski, Obras Escogidas (Vol. 2, pp.287-348). Madrid: Visor Distribuciones.

Vygotski, L. S. (1998). La imaginación y el arte en la infancia. Cidade do México: Hispânica.

Vygotski, L. S. (2001). A educação estética. In L. S. V Psicologia pedagógica (P. Bezerra, Trad. pp.323-378). São Paulo: Martins Fontes.

Zanella, A.V. (2005). Sujeito e alteridade: reflexões a partir da psicologia histórico-cultural. Psicologia e Sociedade, 17(2), 99-104.

Zanella, A. V. (2007). Educación estética y actividad creadora: herramientas para el desarrollo humano. Universitas Psychologica La Revista, 6, 483-492.

Zanella, A. V., Cabral, M. G., Ros, S. Z., Urnau, L. C., Titon, A. P., Werner, F. W., Sander, L., \& Maheirie, K. (2006). Relações estéticas, atividade criadora e constituição do sujeito: reflexões sobre a formação de professores(as). Cadernos de Psicopedagogia, 6, 0-6.

Zanella, A. V., \& Sais, A. P. (2008). Reflexões sobre o pesquisar em psicologia como processo de criação ético, estético e político. Análise Psicológica, 26(4), 679-687. 